\title{
Prediction of Flow Duration Curves for Ungauged Basins with Quasi-Newton Method
}

\author{
Mutlu Yaşar*, Neset Orhan Baykan \\ Department of Civil Engineering, Pamukkale University, Denizli, Turkey \\ Email: ${ }^{*}$ mutluyasar@pau.edu.tr
}

Received November 5, 2012; revised December 6, 2012; accepted December 14, 2012

\begin{abstract}
Prediction of flow-duration-curves (FDC) is an important task for water resources planning, management and hydraulic energy production. Classification of the basins as carstic and non-carstic may be used to estimate parameters of the FDC with predictive tools for catchments with/without observed stream flow. There is a need for obtaining FDC for ungauged stations for efficient water resource planning. Thus, study proposes a quite new approach, called the EREFDC model, for estimating the parameters of the FDC for which the parameters of the FDC are obtained with quasi-Newton method. Estimation are made for using the bv gauged stations at first than the FDC parameters are estimated for ungauged stations based on drainage area, annual mean precipitation, mean permeability, mean slope, latitude, longitude, and elevation from the mean sea level are used. The EREFDC model consists of various type of linear- and nonlinear mathematical equations, is able to predict a wide range of the FDC parameters for gauged and ungauged basins. The method is applied to 72 unimpaired catchments studied are about for 50 years average daily measured stream flow. Results showed that the EREFDC model may be used for estimating. FDC parameters for ungauged hydrological basins in order to find FDC for ungauged stations. Results also showed that the EREFDC model performs better in carstic regions than non-carstic regions. In addition, parameters of FDC for tributaries at the basins with insufficient flow data or without flow data may be determined by using basin characteristics.
\end{abstract}

Keywords: Flow Duration Curve; Optimization; BFGS Algorithm; Basin Characteristics

\section{Introduction}

Efficient use of energy sources is a major problem all over the world, especially renewable energy that is a core prerequisite for sustainable development. Hydroelectric energy is one of the sustainable energy sources that need to be carefully planned for future generations. Moreover, technological developments require gradually increasing energy needs in the future, but, it is usually not equally distributed in place and time in the world.

Modeling a flow duration curve (FDC) is essential for the power plants where the measurement could not be performed and the plants are run-of-the river type. This is one of the main the reason why hydrologists give so much importance to this subject. In addition, prediction of FDCs in ungauged stations are still challenging problem for hydrological community.

One way of efficient planning and use of hydroelectric energy require good measured data for all stream flows around the hydrological basins. This is usually impossible since it requires considerable amount of money and for gauging all the basins. Thus it needs to be method that

${ }^{*}$ Corresponding author. deals with the parameter estimation of flow-durationcurves (FDC) for gauged and ungauged basins. The FDC is a parametric methods that supplies the necessary information for the various water resource applications [1]. The values of daily FDCs present the most valuable information for the regional regime of flow during hydroelectric power station application in a streambed [2]. In addition, a stream flow system can be defined by a FDC showing the distribution of flow frequencies obtained from measured flows. If the data are unattainable or limited, plenty of sources should be evaluated. Therefore, for the places where measurements cannot be carried out estimation of FDCs is needed. An experimental FDC can be easily obtained from flow observations by using standard nonparametric processes. The regionalization of a FDC is important when working with basins without gauging stations and shortage of flow data.

The usefulness of FDC is that it is a main input for Hydroelectric Power Plants (HEPP) that is classified into two main groups: 1) The HEPP with stored, regulated, and directly diverted of natural flows; and 2) The HEPP with storage reservoirs for which the flows have random characters in time and they are regulated by means of 
storing so that reliable and firm energy may be obtained by using this regulated amount of water. In the case of nonstored HEPP's, energy is to be produced in the powerhouse changes as a function of the existing flow value in the river bed if there is no storage area due to the topography. Therefore, this type of HEPP requires realestimation of flow quantity for relevant design and efficient use of stream flow.

Long term hydrologic data are generally not available in many hydrological basins. Annual mean flow values are commonly considered in many hydrologic designstudies. In order to obtain daily flow data at projectedpoint, an index-station of long-term observation values is selected considering similar geographical conditions. If the annual flow data are persistent and representative for the region, the data transfer is assumed to be done properly. It is known that the FDC are synthetic (artificial) curves so that the occurrences of the flows are disturbed by putting the flows to descending or ascending order. FDC is not a cumulative probability curve because the time series of the flows in a stream are not stationery for the intervals less than a year, so that the statistical characteristics change along the year like mean, standard deviation, and coefficient of skewness. Therefore, the exceedence probability of the flow in a certain day depends on the day where it is placed in [3]. If a generalized FDC is drawn for each stream basin with observed data, the FDC with a certain errata may be obtained for the basins of nongauged stations.

Fennessey and Vogel [4] developed flow duration curves for the regions without adjustment and gauging station in Massachusetts and they analyzed the new models related with the regional flow duration curves. FDCs they found that have a complex structure requiring probability density functions with frequently three or more parameters. They approximated daily FDCs by utilizing twoparameter lognormal probability density function. Mimikou and Kaemaki [5] regionalized the flow duration curve by using the morpho-climatological properties of the drainage basin. They explained the regional variability of the flow duration curve associated with every parameter with the help of multiple regression techniques by using annual mean regional precipitation, basin area, hypsometric head and stream length. Alkan [6] suggested the dimensionless FDC uses from in Equation (1).

$$
Q=\alpha \mathrm{e}^{-\beta t}
$$

where, then, $Q$ is the flow $\left(\mathrm{m}^{3} / \mathrm{sec}\right), t$ is the time series, $\alpha$ and $\beta$ are the parameters of the FDC. Alkan [6] found that there is a nonlinear dependence between the natural logarithm of the initial value of the exponential model parameters and natural logarithm of coefficient of annual flows. This parametric model has been employed to the stream gauging stations in carstic and non-carstic basins in Turkey. Singh et al. [7] made modeling of the FDCs for the small water projects without gauging stations and the basins with insufficient measurements in the Himalayas. Dimensionless FDCs were obtained by using normal, lognormal and exponential conversions from basins with gauging stations to the basins without gauging stations. Yu and Yang [8] obtained FDCs for Cho-Shuei Creek in Taiwan and they tested the validity of the FDCs. They determined that polynomial method contains less uncertainty compared to area index method according to the analyses of uncertainty of obtained FDCs.

The studies on the deficiencies of flow measurements are carried out by many researchers in many places in the world such as Greece [5], the USA [4], Italy [9], India [7], Taiwan [10] and Portugal [11]. Crocker et al. [11] aimed to obtain a regional model in order to estimate the FDC for basins without measurements in some parts of Portugal. They used cumulative distribution function to combine a model used in estimation of a FDC when flow is not zero and a model used in estimation of the period, in percentage, when there is no stream [11]. Cole et al. [12] indicated that the users of flow data need independent qualification indicator in order to use the data safely and they suggested the use of long term FDCs as an indicator. This method lights the way visually for the disorder in flow data and gives the place and the form of the fault.

Krasovskaia et al. [13] developed a model to estimate a FDC for the basins without gauging stations. FDCs were obtained experimentally by using a medium value and a distribution coefficient and then, they were made definable as regional FDCs or theoretical regional curves. Development of first degree moments of FDCs along a river system and their local scale like a basin area were analyzed as well as interpolations along the river system were prepared carefully. Daily flow data of Costa Rica were used in the study. Estimation errors are relatively about $30 \%$ higher for a period longer than $85 \%$. However, for a period lower than $20 \%$ and in the center of a FDC, they become smaller about $10 \%$ and $8 \%$, respectively. The differences between experimental and theoretical FDCs are low and better results were obtained in the center parts of a FDC.

Bari and Islam [14] applied a stochastic approach in order to obtain a FDC associated with a one year period and get rid of difficulties of a traditional FDC in which the date order of flows are masked. They investigated the theoretical development of a stochastic FDC and probability distribution suitable to the average daily flow distribution. The model was applied to the chosen four streams of Bangladesh. Small catchment areas are very important for the development of local water resources. As long as the global pressure on water resources increases, the potential of the drainage areas will continue to increase. Generally, the highland catchment areas with 
important water resources are suitable for the development of small hydroelectric energies. Estimation of a FDC is important for the design of hydraulic structures and related environmental assessment.

Niadas [15] suggested an approach about development of symbolic daily FDCs for small catchment areas by combining regional data with real instant flow data. Annual mean flow values were estimated by using instant flow data of the two regions in representation of the flow regime statistically.

Castellarin et al. [16] showed the relation between the frequency and dimension of the overflow in a FDC. Their study also aimed to estimate the FDC of streams without flow values by evaluating the efficiency and correctness of the data. The study was carried out for a large area in east Italy. In order to evaluate the uncertainty of the regional FDCs, they accepted the jack-knife cross validation method. Results included: a) The evaluation of reliability of regional FDCs for imponderable areas; b) the closeness of reliability data for the best three regional models presented; and c) The empirical FDC's based on limited data samples generally provide a better fit of the long-term FDC's than regional FDC's.

Ming et al. [17] proposed an index model for predicting the FDCs. The proposed index model was defined as nonparametric relationship between each parameter to the predictive tools and a linear combination of predictors. They found that the index model improved the prediction performance for ungauged stations. Similar study was due to Ganora et al. [18], where distance-based model was used to predict FDC for ungauged stations. They found that the distance-based model produced better estimates of the flow duration curves using only few catchment descriptors. Yokoo and Sivapalan [19] proposed an FDC curve reconstruction with climatic and landscape controls. Similar study was carried out by Viola et al. [20] for which the regional FDC was obtained in Sicily. The regional regression estimates were proposed in that study.

In all approaches involving the regionalization of FDCs, the applicability of the estimation methods for the small catchment areas for ungauged stations is quite limited. In addition, use of regression techniques developed so far for the regional estimations may not best represent the basin characteristics. Therefore, accurate estimations for small catchment areas need to be made with proper mathematical equations with commonly obtainable data for the region such as drainage area, mean precipitation rate, etc. Moreover there are many studies on the prediction of FDC curve with linear regression techniques and the statistical methods, but there is limited study on estimation of the FDC with nonlinear equations with regional parameters. One way of estimating the FDC parameters may be use of numerical method such as quasiNewton method. The most popular quasi-Newton algo- rithm is the BFGS method, named by its discoverers Broyden, Fletcher, Goldfarb, and Shanno. The BFGS method is derived from the Newton's method in optimization, a class of hill-climbing optimization techniques that seeks the stationary point of a function, where the gradient is zero. Newton's method assumes that the function can be locally approximated as a quadratic Taylor expansion in the region around the optimum, and uses the first and second derivatives to find the stationary point. Many nonlinear equations for FDC parameter estimation are solved with the BFGS algorithm using the tools in Excel solver [21]. The $\alpha$ and $\beta$ parameters given in Equation (1) of the FDC are subsequently solved with solver tool in Excel by minimizing observed and estimated values of stream flow by using drainage area, annual mean precipitation, mean permeability, mean slope, latitude, longitude, and elevation from the mean sea level. During the estimation, the $\alpha$ and $\beta$ parameters are obtained by an parametric Equation given in (1) at first for each gauged stations, then by using regional parameters (such as drainage are, mean slope, etc.) as an independent variable, $\alpha$ and $\beta$ parameters are regionalized with set of linear and nonlinear equations given in Section 2 .

The data need for estimating the parameters of FDC curves are obtained from US Geological Survey (USGS). The detailed information about the method [22] carried out in the USA applications in which the data transfer is performed for the imponderable area with the correlation between concurrent flows can be attained from USGS articles and reports $[23,24]$.

The rest of the paper is organized as follows: The next section is about model development. Section 3 is about BFGS algorithm. Section 4 is on data collection and evaluation and finally, conclusions are given in Section 5.

\section{Model Development}

Modeling procedure is carried out in two steps: Step
tions

Step I: Obtaining parameters for each gauging sta-

The parameters of FDC for each of the gauged stations are obtained in Equation (1). In order to obtain the $\alpha$ and $\beta$ parameters, in Equation (1) the average daily flows data are used for each stations that is averaged over 60 years of measured daily flow. Average daily flow for one-year long period are put into an order from maximum to minimum as referenced to a beginning of the January first for that year. Typical FDC curve are given in Figure 1 for station 1, named Pawnee R. at Rozel, in Kansas. As can be seen in Figure 1, the fitted FDC and measured FDC cure are in good agreement with the theoretical FDC. Estimating the parameters of $\alpha$ and $\beta$ are obtained first for each of the stations, and then the regionalization is made at Step II. 


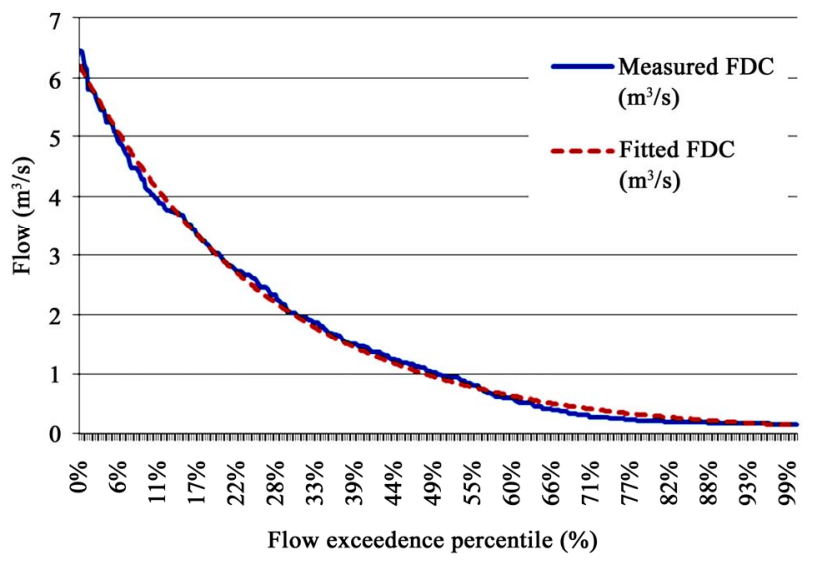

Figure 1. Typical FDC curve of Pawnee R. at Rozel, in Kansas.

At Step I, the $\alpha$ and $\beta$ parameters are calculated for each gauging stations by minimizing Equation (2) as:

$$
\operatorname{Min}(S S E)=\sum_{t=1}^{T}\left(Q-Q_{e s t}\right)
$$

where $S S E$ is the sum of squared errors between observed stream flows, $Q$, estimated stream flow $Q_{\text {est }}$, and $T$ is the total number of daily observed stream flow. That is set as $T=365$. During solution quasi-Newton method with solver toolbox are used.

\section{Step II. Regionalization}

By using the $\alpha$ and $\beta$ parameters obtained. at Step I, the regionalization is carried out at Step II by using the regional parameters as drainage area (DA), annual mean precipitation (AMP), mean permeability (MP), mean slope (MS), latitude (LAT), longitude (LONG), and elevation from the mean sea level (EL). Equations are given in Equations (3) and (4).

$$
\begin{aligned}
\alpha= & \omega_{0}+\omega_{1} * x_{1}^{\omega_{2}}+\omega_{3} * x_{2}^{\omega_{4}}+\omega_{5} * x_{3}^{\omega_{6}}+\omega_{7} * x_{4}^{\omega_{8}} \\
& +\omega_{9} * x_{5}^{\omega_{10}}+\omega_{11} * x_{6}^{\omega_{12}}+\omega_{13} * x_{7}^{\omega_{14}} \\
\beta= & \omega_{0}+\omega_{1} * x_{1}^{\omega_{2}}+\omega_{3} * x_{2}^{\omega_{4}}+\omega_{5} * x_{3}^{\omega_{6}}+\omega_{7} * x_{4}^{\omega_{8}} \\
& +\omega_{9} * x_{5}^{\omega_{10}}+\omega_{11} * x_{6}^{\omega_{12}}+\omega_{13} * x_{7}^{\omega_{14}}
\end{aligned}
$$

$x_{1}=$ Drainage area $\left(\mathrm{km}^{2}\right)$;

$x_{2}=$ Annual mean precipitation $(\mathrm{mm})$;

$x_{3}=$ Mean permeability $(\mathrm{mm} / \mathrm{h})$;

$x_{4}=$ Mean slope $(\%)$;

$x_{5}=$ Latitude $\left({ }^{\circ}\right) ; \mathrm{x}_{6}=$ Longitude $\left({ }^{\circ}\right)$;

$x_{7}=$ Elevation $(\mathrm{mm})$.

where, $\omega$ are the weighting coefficient of the nonlinear equations. It is quite difficult for field engineers to use the FDC directly given in Equations (3) and (4) since most of them may not have the optimization knowledge; Thus, the $\alpha$ and $\beta$ parameters are obtained by quasiNewton method so called BFGS given in Section 3. Before applying Equations (3) and (4), the hydrological basins are clustered into two groups as carstic and noncarstic. The reason for clustering is a discharge difference between carstic and non-carstic regions in terms of drainage and flow characteristics.

Equations (3) and (4) are used to solve Equations (5) and (6) during solution process, the following objective functions are used:

$$
\begin{aligned}
& \min (S S E)=\sum_{i=1}^{I}\left(\alpha-\alpha_{\text {pre }}\right) \\
& \min (S S E)=\sum_{i=1}^{I}\left(\beta-\beta_{\text {pre }}\right)
\end{aligned}
$$

where, $I$ is the total number of gauged stations for each carstic and non-carstic groups, $\alpha$ and $\beta$ are the FDC parameters obtained from Step I, $\alpha_{\text {pre }}$ and $\beta_{\text {pre }}$ are the predicted values.

Flowchart of the proposed Estimation of REgionalized Flow Duration Curve (EREFDC) is given in Figure 2. As can be seen in Figure 2, the EREFDC model starts with obtaining the parameters of FDC firs and then by using the regional geographical and hydrological parameters, the parameters of the EREFDC are obtained using the quasi-Newton method as given in Figure 2.

\section{BFGS Algorithm}

The most popular quasi-Newton algorithm is the BFGS method, named by its discoverers Broyden, Fletcher, Goldfarb, and Shanno. The BFGS method is derived from the Newton's method in optimization, a class of hillclimbing optimization techniques that seeks the stationary point of a function, where the gradient is zero. Newton's method assumes that the function can be locally approximated as a quadratic Taylor expansion in the region around the optimum, and uses the first and second derivatives to find the stationary point. Detailed discussion of BFGS method can be found in some numerical optimization textbooks, see the references [25,26]. The BFGS algorithm can be summarized as follows [26,27]:

Step 1: Estimate an initial design vector $\mathbf{X}^{(0)}$. Choose a symmetric positive definite matrix $\mathbf{H}^{(0)}$ as an estimate for the Hessian of the cost function. In the absence of more information, let $\mathbf{H}^{(0)}=\mathbf{I}$. Choose a convergence parameter $\varepsilon$. Set $k=0$, and compute the gradient vector as $\mathbf{c}^{(0)}=\nabla g\left(\mathbf{X}^{(0)}\right)$. Where, $k$ is iteration index and $g$ is the cost function of the design vector.

Step 2: Calculate the norm of the gradient vector as $\left\|\mathbf{c}^{(k)}\right\|$. If $\left\|\mathbf{c}^{(k)}\right\|<\varepsilon$, then stop the iterative process; other-

Step 3: Solve the linear system of equations $\mathbf{H}^{(k)} \mathbf{d}^{(k)}=-\mathbf{c}^{(k)}$ to obtain the search direction. Where, $\mathbf{d}$ is search direction vector.

Step 4: Compute optimum step size $\alpha_{k}=\alpha$ to mini$\operatorname{mize} \mathbf{g}\left(\mathbf{X}^{(k)}+\alpha \mathbf{d}^{(k)}\right)$ 


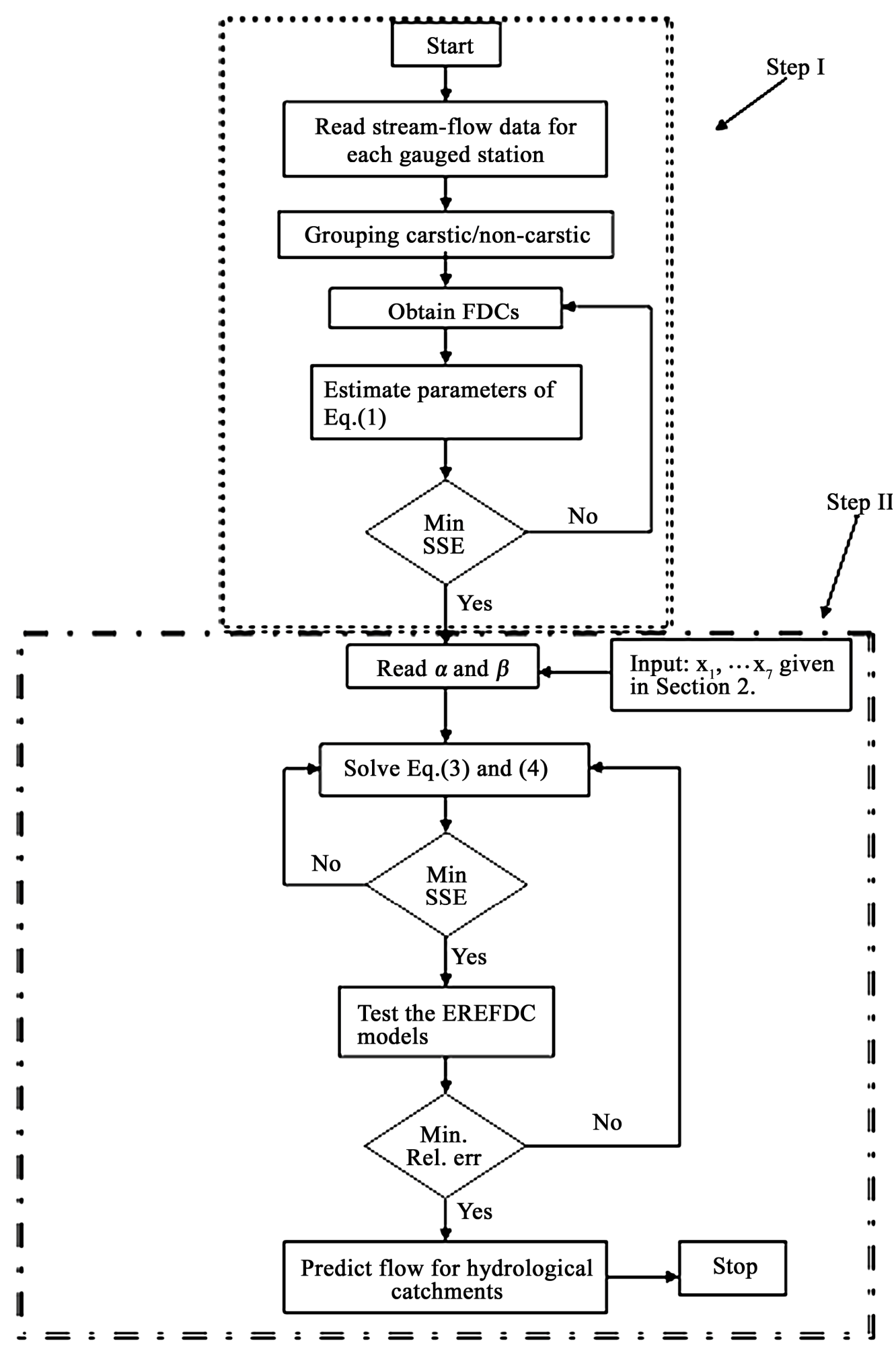

Figure 2. Flow-chart of EREFDC.

Step 5: Update the design as $\mathbf{X}^{(k+1)}=\mathbf{X}^{(k)}+\alpha \mathbf{d}^{(k)}$.

Step 6: Update the Hessian approximation for the cost function as

$$
\mathbf{H}^{(k+1)}=\mathbf{H}^{(k)}+\mathbf{D}^{(k)}+\mathbf{E}^{(k)}
$$

where the correction matrices $\mathbf{D}^{(k)}$ and $\mathbf{E}^{(k)}$ are given as

$$
\mathbf{D}^{(k)}=\frac{\mathbf{y}^{(k)} \mathbf{y}^{(k)^{T}}}{\mathbf{y}^{(k)} \mathbf{s}^{(k)}} ; \mathbf{E}^{(k)}=\frac{\mathbf{c}^{(k)} \mathbf{c}^{(k)^{T}}}{\mathbf{c}^{(k)} \mathbf{d}^{(k)}}
$$


$\mathbf{s}^{(k)}=\alpha_{k} \mathbf{d}^{(k)} \quad$ (change in design);

$\mathbf{y}^{(k)}=\mathbf{c}^{(k+1)}-\mathbf{c}^{(k)} \quad$ (change in gradient);

$\mathbf{c}^{(k+1)}=\nabla g\left(\mathbf{X}^{(k+1)}\right)$

Step 7: Set $k=k+1$ and go to Step 2 .

\section{The EREFDC Model Application}

\subsection{Data Collection}

This study uses average daily stream flow data for 72 catchments in Kansas city in America. Kansas is the 15th largest state of the USA with area of $213.089 \mathrm{~km}^{2}$. The stream flow data are for relatively unimpaired catchments. The catchment size ranges from 120 to $30,000 \mathrm{~km}^{2}$ and data length varies from 20 to 100 years. The available data in Kansas City has been downloaded from the source: http://waterdata.usgs.gov. Elevation, mean slope permeability and precipitation are taken from Perry et al. [28].

\subsubsection{Flow Data}

The stations used in the EREFDC modeling studies are selected from those are not affected from the rate of the flow namely uncontrolled flow. Stations and their corresponding data are given in Table 1. As can be seen in Table 1 drainage area varies between $10-3100 \mathrm{~km}^{2}$, annual precipitation varies between $100-1000 \mathrm{~mm}$, average basin permeability varies between 10 and 140 $\mathrm{mm} / \mathrm{h}$, the slope of the basin varies between $0.8 \%-6.0 \%$ and the elevation value varies between $200-800 \mathrm{~m}$.

Each of station includes a data from an average daily stream flow that has a length of 366 data in a year. One example of the data are given in Appendix for station number 6814000 Turkey C. 72 station are taken into account during the EREFDC model developments since there are no homogenous data on other station in the basin in Kansas city, USA. Data are classified as carstic and non-carstic group by putting them into an order according to the minimum and maximum station number. $80 \%$ of the carstic and non-carstic data are used for ERECFDC model development and $20 \%$ of them are used for EREFDC model testing.

Carstic map are given in Figure 3. In order to find Figure 3, each gauged stations are extracted according to their coordinates, then those coordinates matched with carst maps taken from http//:pubs.usgs.gov/of/2004/1352/.

Table 1. Station numbers and their corresponding physical and geographical.

\begin{tabular}{|c|c|c|c|c|c|c|c|c|}
\hline $\begin{array}{l}\text { Station } \\
\text { Number }\end{array}$ & $\begin{array}{l}\text { Station } \\
\text { Name }\end{array}$ & $\begin{array}{c}\text { Drainage Area } \\
x_{1}\left(\mathrm{~km}^{2}\right)\end{array}$ & $\begin{array}{c}\text { Annual Mean } \\
\text { Precipitation } \\
x_{2}(\mathrm{~mm})\end{array}$ & $\begin{array}{c}\text { Mean } \\
\text { Perme-ability } \\
x_{3}(\mathrm{~mm} / \mathrm{h})\end{array}$ & $\begin{array}{c}\text { Mean Slope } \\
x_{4}(\%)\end{array}$ & $\begin{array}{c}\text { Latitude } \\
x_{5}\left({ }^{\circ}\right)\end{array}$ & $\begin{array}{c}\text { Longitude } \\
x_{6}\left({ }^{\circ}\right)\end{array}$ & $\begin{array}{c}\text { Elevation } \\
x_{7}(\mathrm{~mm})\end{array}$ \\
\hline 6814000 & Turkey C. & 714.8 & 822 & 12 & 3.10 & 39.9 & 96.1 & 316.2 \\
\hline 6815000 & Big Nemaha R. & 3468 & 827 & 13 & 2.80 & 40.0 & 95.6 & 261.6 \\
\hline 6848500 & Praire Dog & 2608.1 & 548 & 35 & 2.10 & 40.0 & 99.5 & 614.5 \\
\hline 6860000 & Smooky Hill R. & 9207.5 & 449 & 39 & 1.30 & 38.8 & 100.9 & 799.4 \\
\hline 6861000 & Smooky Hill & 13519 & 468 & 39 & 1.40 & 38.8 & 100.0 & 669.4 \\
\hline 6863500 & Big C. & 1538.5 & 554 & 30 & 1.40 & 38.9 & 99.3 & 595.5 \\
\hline 6866500 & Smooky Hill R. & 21647 & 529 & 37 & 1.60 & 38.7 & 97.6 & 378.0 \\
\hline 6866900 & Saline R. & 1802.6 & 523 & 35 & 1.50 & 39.1 & 99.9 & 675.9 \\
\hline 6867000 & Saline R. & 3890.2 & 551 & 35 & 2.20 & 39.0 & 98.9 & 472.9 \\
\hline 6869500 & Saline R. & 7303.8 & 602 & 33 & 2.50 & 39.0 & 97.9 & 385.7 \\
\hline 6871000 & N. Fork Sol. R. & 2198.9 & 541 & 34 & 2.50 & 39.7 & 99.3 & 534.6 \\
\hline 6873000 & South Fork Sol. & 2693.6 & 530 & 37 & 2.10 & 39.4 & 99.6 & 589.3 \\
\hline 6876700 & Salt C. & 994.6 & 685 & 28 & 2.60 & 39.1 & 97.8 & 380.1 \\
\hline 6878000 & Chapman C. & 777 & 785 & 26 & 2.20 & 39.0 & 97.0 & 336.0 \\
\hline 6879650 & Kings C. & 714.00 & 838 & 12 & 5.90 & 39.1 & 96.6 & 333.6 \\
\hline 6882000 & Big Blue R. & 11517 & 725 & 21 & 1.30 & 40.0 & 96.6 & 354.2 \\
\hline 6882510 & Big Blue R. & 12372 & 728 & 21 & 1.40 & 39.8 & 96.7 & 338.4 \\
\hline 6884000 & Little Blue R. & 6086.5 & 694 & 36 & 1.40 & 40.1 & 97.2 & 389.3 \\
\hline 6884025 & Little Blue R. & 7127.7 & 702 & 35 & 1.60 & 40.0 & 97.0 & 370.7 \\
\hline 6884200 & Mill C. & 891 & 778 & 23 & 2.40 & 39.8 & 97.0 & 384.5 \\
\hline
\end{tabular}




\section{Continued}

\begin{tabular}{|c|c|c|c|c|c|c|c|c|}
\hline 6884400 & Little Blue R. & 8609.2 & 717 & 33 & 1.70 & 39.7 & 96.8 & 347.5 \\
\hline 6885500 & B. Vermillion R. & 1061.9 & 846 & 9 & 2.40 & 39.7 & 96.4 & 337.4 \\
\hline 6888000 & Vermillion C. & 629.4 & 887 & 11 & 3.40 & 39.3 & 96.2 & 302.4 \\
\hline 6884200 & Mill C. & 891 & 778 & 23 & 2.40 & 39.8 & 97.0 & 384.5 \\
\hline 6884400 & Little Blue R. & 8609.2 & 717 & 33 & 1.70 & 39.7 & 96.8 & 347.5 \\
\hline 6885500 & B. Vermillion R. & 1061.9 & 846 & 9 & 2.40 & 39.7 & 96.4 & 337.4 \\
\hline 6888000 & Vermillion C. & 629.4 & 887 & 11 & 3.40 & 39.3 & 96.2 & 302.4 \\
\hline 6888500 & Mill C. & 818.4 & 881 & 13 & 4.20 & 39.1 & 96.2 & 294.1 \\
\hline 6889200 & Soldier C. & 406.6 & 905 & 12 & 3.20 & 39.2 & 95.9 & 281.7 \\
\hline 6889500 & Soldier C. & 751.1 & 908 & 14 & 3.30 & 39.1 & 95.7 & 263.0 \\
\hline 6890100 & Delaware R. & 1116.3 & 914 & 10 & 3.10 & 39.5 & 95.5 & 280.7 \\
\hline 6891500 & Wakarusa R. & 1100.8 & 930 & 16 & 2.60 & 38.9 & 95.3 & 243.6 \\
\hline 6892000 & Stranger C. & 1051.5 & 962 & 13 & 3.20 & 39.1 & 95.0 & 244.1 \\
\hline 6893080 & Blue R. & 119.1 & 999 & 15 & 2.10 & 38.8 & 94.7 & 270.1 \\
\hline 6910800 & M. des Cygnes R. & 458.4 & 909 & 10 & 2.20 & 38.6 & 96.0 & 319.5 \\
\hline 6911000 & M.des Cygnes R. & 909.1 & 930 & 11 & 2.20 & 38.5 & 95.7 & 287.1 \\
\hline 6911900 & Dragoon C. & 295.3 & 916 & 11 & 2.70 & 38.7 & 95.8 & 309.7 \\
\hline 6912500 & $\mathrm{H}$ and $\mathrm{T}$ Mile $\mathrm{C}$. & 834 & 920 & 12 & 2.30 & 38.6 & 95.6 & 280.1 \\
\hline 6913000 & M. des Cygnes R. & 2693.6 & 928 & 12 & 2.20 & 38.6 & 95.5 & 272.4 \\
\hline 6913500 & M. des Cygnes R. & 3237.5 & 932 & 13 & 2.20 & 38.6 & 95.3 & 261.4 \\
\hline 6914650 & Big Bull C. & 380.7 & 997 & 17 & 2.10 & 38.7 & 94.9 & 260.4 \\
\hline 6917000 & Little Osage R. & 764.1 & 103 & 18 & 2.00 & 38.0 & 94.7 & 235.3 \\
\hline 7140850 & Pawnee R. & 3242.68 & 520 & 28 & 1.10 & 38.2 & 99.6 & 640.9 \\
\hline 7141200 & Pawnee R. & 5563.3 & 533 & 28 & 1.10 & 38.2 & 99.4 & 621.9 \\
\hline 7141780 & Walnut C. & 3087.3 & 534 & 30 & 1.10 & 38.5 & 99.4 & 610.9 \\
\hline 7141900 & Walnut C. & 3651.9 & 544 & 30 & 1.20 & 38.5 & 99.0 & 578.3 \\
\hline 7142575 & Rattlesnake C. & 2711.7 & 620 & 150 & 0.70 & 38.1 & 98.5 & 544.1 \\
\hline 7143300 & Cow C. & 1885.5 & 664 & 33 & 0.90 & 38.3 & 98.2 & 496.3 \\
\hline 7143665 & Little Arkansas R. & 1906.2 & 749 & 53 & 0.80 & 38.1 & 97.6 & 424.1 \\
\hline 7144200 & Little Arkansas R. & 3436.9 & 771 & 51 & 0.80 & 37.8 & 97.4 & 404.1 \\
\hline 7144780 & N.Fork Nin. R. & 2038.3 & 682 & 139 & 0.70 & 37.9 & 98.0 & 443.8 \\
\hline 7145200 & S. Ninnescah R. & 1683.5 & 692 & 78 & 1.30 & 37.6 & 97.9 & 413.9 \\
\hline 7145500 & Ninnescah R. & 5514.1 & 713 & 96 & 1.10 & 37.5 & 97.4 & 372.6 \\
\hline 7145700 & Slate C. & 398.9 & 781 & 22 & 0.80 & 37.2 & 97.4 & 352.7 \\
\hline 7147070 & Whitewater R. & 1103.3 & 839 & 12 & 1.20 & 37.8 & 97.0 & 375.4 \\
\hline 7147800 & Walnut R. & 4869.2 & 871 & 12 & 1.40 & 37.2 & 97.0 & 330.1 \\
\hline 7149000 & Medicine Lodge R. & 2338.8 & 647 & 65 & 2.70 & 37.0 & 98.5 & 392.3 \\
\hline 7151500 & Chikaskia R. & 2056.5 & 729 & 67 & 1.10 & 37.1 & 97.6 & 337.7 \\
\hline 7152000 & Chikaskia R. & 4814.8 & 837 & 20 & 1.00 & 36.8 & 97.3 & 294.9 \\
\hline 7154500 & Cimarron R. & 2864.5 & 414 & 53 & 1.00 & 36.9 & 103.0 & 1299.0 \\
\hline 7156900 & Cimarron R. & 22108 & 428 & 80 & 1.10 & 37.0 & 100.5 & 707.2 \\
\hline 7157500 & Crooked C. & 2996.6 & 521 & 42 & 0.72 & 37.0 & 100.2 & 659.5 \\
\hline 7157950 & Cimarron R. & 31090 & 496 & 81 & 1.30 & 36.9 & 99.3 & 487.6 \\
\hline 7166500 & Verdigris R. & 2947.4 & 953 & 17 & 2.40 & 37.5 & 95.7 & 237.8 \\
\hline 7167500 & Otter C. & 334.1 & 919 & 12 & 2.80 & 37.7 & 96.2 & 298.0 \\
\hline 7169500 & Fall R. & 2141.9 & 921 & 16 & 2.70 & 37.5 & 95.8 & 249.7 \\
\hline 7169800 & Elk R. & 569.8 & 926 & 11 & 0.50 & 37.4 & 96.2 & 273.5 \\
\hline 7172000 & Caney R. & 1152.6 & 902 & 14 & 3.20 & 37.0 & 96.3 & 232.7 \\
\hline 7174400 & Caney R. & 3605.3 & 933 & 25 & 3.10 & 36.8 & 96.0 & 199.1 \\
\hline 7179500 & Neosho R. & 647.5 & 858 & 11 & 1.80 & 38.7 & 96.5 & 367.5 \\
\hline 7180500 & Cedar C. & 284.9 & 847 & 13 & 1.60 & 38.2 & 96.8 & 384.8 \\
\hline 7183500 & Neosho R. & 12704 & 924 & 15 & 1.70 & 37.3 & 95.1 & 247.0 \\
\hline 7184000 & Lightning C. & 510.2 & 107 & 26 & 1.20 & 37.3 & 95.0 & 249.4 \\
\hline 7186000 & Spring R. & 3014.8 & 110 & 36 & 1.20 & 37.2 & 94.6 & 254.0 \\
\hline 7187000 & Shoal C. & 1105.9 & 109 & 38 & 2.70 & 37.0 & 94.5 & 270.3 \\
\hline 7188000 & Spring R. & 6500.9 & 109 & 36 & 1.40 & 36.9 & 94.7 & 227.5 \\
\hline
\end{tabular}




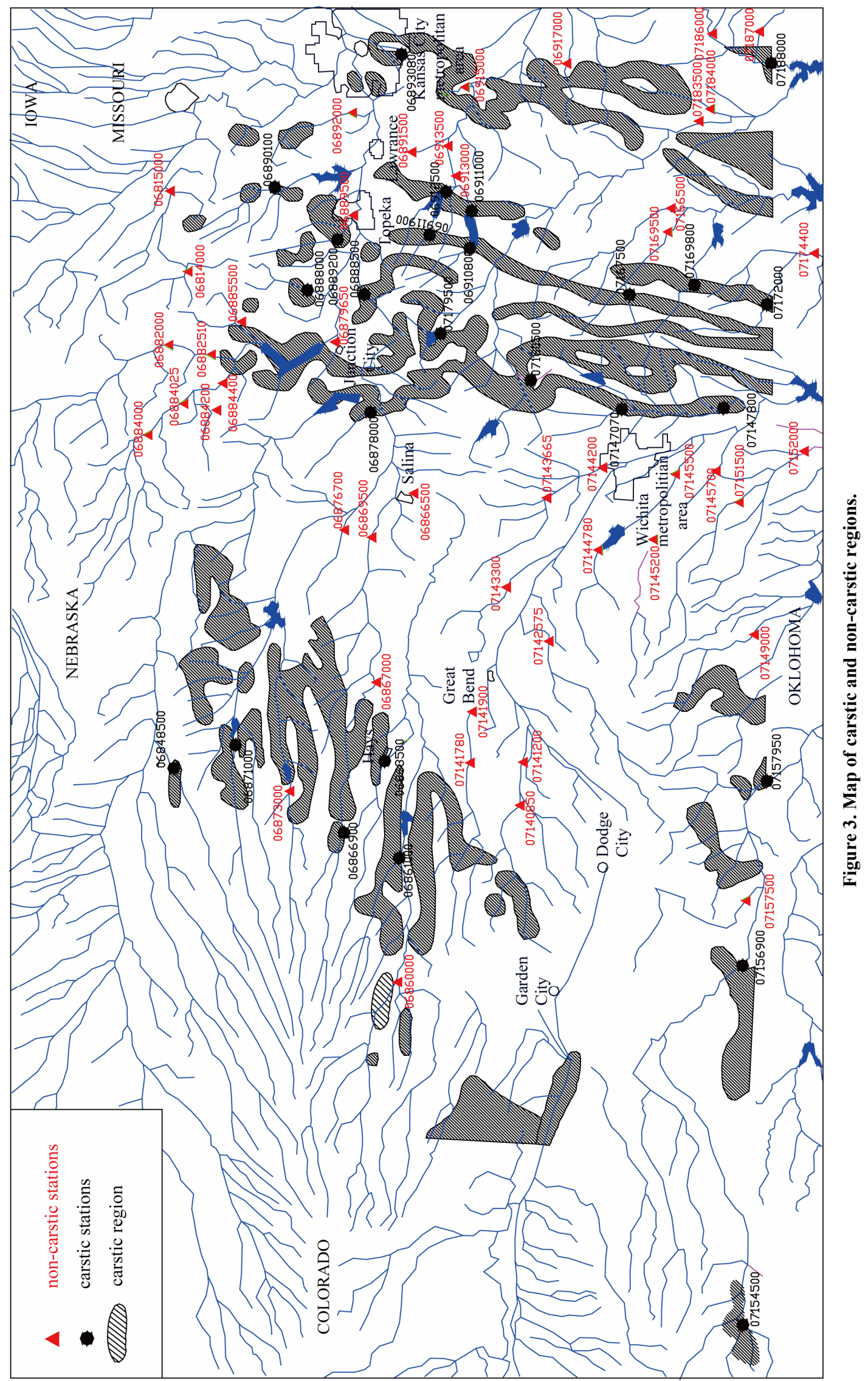


After obtaining carstic maps, stations are grouped according to carstic and non-carstic region.

\subsubsection{Data Generation}

Data generation is carried out at Step I in the following way; Fitted FDC parameters defined at Step I are obtained by solver toolbox and the values are given in Tables 2(a) and (b). As can be seen in Tables 2(a) and (b), coefficient of determination $\mathrm{R}^{2}$ varies $44 \%$ to $98 \%$. The reason for low $\mathrm{R}^{2}$ at stations 714275 and 7154500 may be the measurement error or nonhomogeneity for the stream flow data

Tables 2(a) and (b) show the non-carstic and carstic data among the 72 gauged stations and 46 of them are non-carstic group and 26 of them are carstic.

\subsection{The EREFDC Application and Regionalization}

The EREFDC model is applied to 21 carstic and 37 noncarstic uncontrolled measured flows for estimating the parameters of the EREFDC models. The 5 of the carstic and 9 of the non-carstic stations are used for testing the EREFDC. Considering carstic stations, predicted EREFDC model parameters for $\alpha$ and $\beta$ are given in Equations (7) and (8), respectively. Similarly, EREFDC model parameters for $\alpha$ and $\beta$ considering non-carstic stations, are given in Equations (9) and (10), respectively.

$$
\begin{aligned}
\operatorname{EREFDC}_{\alpha}= & (-4412.54)+\left(456.05 * x_{1}^{0.02}\right) \\
& +\left(5371.2 * x_{2}^{-0.76}\right)+\left(4078.42 * x_{3}^{-0.01}\right) \\
& +\left(98.11 * x_{5}^{-4.25}\right)+\left(-0.36 * x_{6}^{1.27}\right) \\
& +\left(-4893.3 * x_{7}^{-293.67}\right) \\
\text { EREFDC }_{\beta}= & (-0.07)+\left(-0.14 * x_{2}^{-0.72}\right) \\
& +\left(-0.69 * x_{5}^{-0.75}\right)+\left(0.90 * x_{6}^{-0.44}\right) \\
\text { EREFDC }_{\alpha}= & (-2569.72)+\left(2061.77 * x_{1}^{0.02}\right) \\
+ & \left(295.91 * x_{2}^{-25.45}\right)+\left(10.45 * x_{4}^{-0.76}\right) \\
+ & \left(114.25 * x_{5}^{-31.45}\right)+\left(0.84 * x_{6}^{1.12}\right) \\
+ & \left(933.44 * x_{7}^{-0.2}\right) \\
E_{B R E D C}= & (-0.34)+\left(0.05 * x_{3}^{-0.03}\right) \\
& +\left(-0.10 * x_{5}^{0.07}\right)+\left(0.02 * x_{6}^{-0.09}\right)
\end{aligned}
$$

\begin{tabular}{|c|c|c|c|c|}
\hline \multirow{2}{*}{$\begin{array}{l}\text { Station } \\
\text { Number }\end{array}$} & \multirow{2}{*}{$\begin{array}{c}\text { Carstic } \\
\text { Non-carstic }\end{array}$} & \multicolumn{3}{|c|}{ Estimated $\alpha, \beta$ parameters for Equation (1) } \\
\hline & & Alfa & Beta & $\mathrm{R}^{2}$ \\
\hline 7142575 & Non-carstic & 3.3173 & 0.0064 & 0.61 \\
\hline 7143300 & Non-carstic & 6.4199 & 0.0076 & 0.97 \\
\hline 7143665 & Non-carstic & 19.2220 & 0.0085 & 0.98 \\
\hline 7144200 & Non-carstic & 22.2665 & 0.0060 & 0.99 \\
\hline 7144780 & Non-carstic & 10.0416 & 0.0061 & 0.75 \\
\hline 7145200 & Non-carstic & 10.7604 & 0.0037 & 0.92 \\
\hline 7145500 & Non-carstic & 30.0664 & 0.0044 & 0.97 \\
\hline 7145700 & Non-carstic & 7.5775 & 0.0092 & 0.98 \\
\hline 7149000 & Non-carstic & 8.4529 & 0.0043 & 0.97 \\
\hline 7151500 & Non-carstic & 19.7044 & 0.0067 & 0.94 \\
\hline 7152000 & Non-carstic & 45.7707 & 0.0065 & 0.98 \\
\hline 7166500 & Non-carstic & 17.4648 & 0.0052 & 0.99 \\
\hline 7169500 & Non-carstic & 34.8421 & 0.0053 & 0.98 \\
\hline 7174400 & Non-carstic & 82.5714 & 0.0060 & 0.99 \\
\hline 7184000 & Non-carstic & 14.6999 & 0.0080 & 0.92 \\
\hline 7186000 & Non-carstic & 57.9585 & 0.0048 & 0.98 \\
\hline 7187000 & Non-carstic & 23.7601 & 0.0042 & 0.97 \\
\hline 7140850 & Non-carstic & 5.2309 & 0.0654 & 0.88 \\
\hline 7157500 & Non-carstic & 2.4943 & 0.0097 & 0.68 \\
\hline 7183500 & Non-carstic & 99.7580 & 0.0029 & 0.92 \\
\hline \multicolumn{5}{|c|}{ (b) } \\
\hline \multirow{2}{*}{$\begin{array}{l}\text { Station } \\
\text { Number }\end{array}$} & \multirow{2}{*}{$\begin{array}{c}\text { Carstic } \\
\text { Non-carstic }\end{array}$} & \multicolumn{3}{|c|}{ Estimated $\alpha, \beta$ parameters for Equation (1) } \\
\hline & & $\alpha$ & $\beta$ & $\mathrm{R}^{2}$ \\
\hline 6848500 & Carstic & 3.3544 & 0.0140 & 0.92 \\
\hline 6861000 & Carstic & 6.6283 & 0.0185 & 0.98 \\
\hline 6863500 & Carstic & 3.6823 & 0.0133 & 0.91 \\
\hline 6866900 & Carstic & 3.8603 & 0.0308 & 0.87 \\
\hline 6871000 & Carstic & 2.7966 & 0.0112 & 0.78 \\
\hline 6878000 & Carstic & 7.4679 & 0.0080 & 0.90 \\
\hline 6888000 & Carstic & 8.8362 & 0.0109 & 0.94 \\
\hline 6888500 & Carstic & 15.0576 & 0.0072 & 0.95 \\
\hline 6889200 & Carstic & 8.3179 & 0.0083 & 0.88 \\
\hline 6890100 & Carstic & 20.7805 & 0.0073 & 0.95 \\
\hline 6893080 & Carstic & 4.0328 & 0.0110 & 0.87 \\
\hline 6910800 & Carstic & 10.5547 & 0.0092 & 0.93 \\
\hline 6911000 & Carstic & 17.0593 & 0.0076 & 0.94 \\
\hline 6911900 & Carstic & 6.8470 & 0.0096 & 0.95 \\
\hline 6912500 & Carstic & 13.7585 & 0.0067 & 0.95 \\
\hline 7147070 & Carstic & 20.8870 & 0.0097 & 0.87 \\
\hline 7147800 & Carstic & 67.2417 & 0.0063 & 0.95 \\
\hline 7154500 & Carstic & 4.0220 & 0.0300 & 0.96 \\
\hline 7156900 & Carstic & 2.1893 & 0.0024 & 0.44 \\
\hline 7157950 & Carstic & 7.3423 & 0.0056 & 0.92 \\
\hline 7167500 & Carstic & 8.3145 & 0.0090 & 0.94 \\
\hline 7169800 & Carstic & 15.1151 & 0.0090 & 0.88 \\
\hline 7172000 & Carstic & 24.2369 & 0.0077 & 0.97 \\
\hline 7179500 & Carstic & 10.2554 & 0.0078 & 0.93 \\
\hline 7188000 & Carstic & 132.0895 & 0.0047 & 0.98 \\
\hline 7180500 & Carstic & 4.9053 & 0.0075 & 0.90 \\
\hline
\end{tabular}

\subsection{The EREFDC Testing}

In order to test the EREFDC model, $20 \%$ of data in Tables 2(a) and (b) are randomly selected for which any of the selected data are not used for during the model devel-
Table 2. (a) Non-carstic grouped and its corresponding estimated parameters at Step I (continued); (b) Carstic grouped data and its corresponding estimated parameters.

(a) 
opment stage. Table 3(a) is for randomly selected noncarstic stations and Table $\mathbf{3 ( b )}$ is for carstic stations.

Estimated FDC and observed FDC are given in Figures 4(a)-(i) for non-carstic stations. Figures are drawn by excluding $10 \%$ and $90 \%$ of flow exceedence percentile.

Figures 5(a)-(e) show the observed and estimated FDC by the EREFDC model for carstic testing stations by excluding $10 \%$ flow exceedence percentile.

Table 4 shows the average relative errors between observed and predicted stream flows obtained by the EREFDC model. The errors given in 3rd column is estimated with an average annual daily stream flow that is averaged over a year, then the average relative errors for testing stations are obtained as given in Table 4. As can be seen in Table 4, The average relative errors varies between $11 \%$ to $88 \%$, but only three of stations, numbered 7,140,850, 7,157,500 and 7,183,500 are not wellfit since the data may probably disordered due to the introduction of hydraulic structure. Table 4 also shows that the relative error for carstic regions is quite better than non-carstic regions.

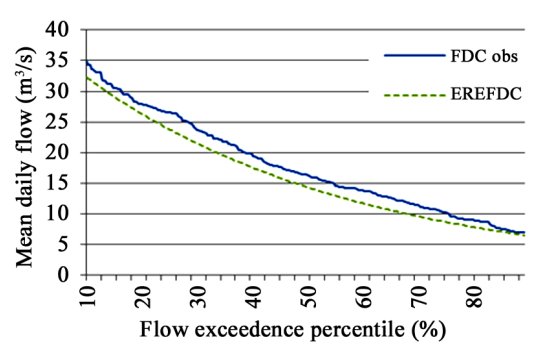

(a)

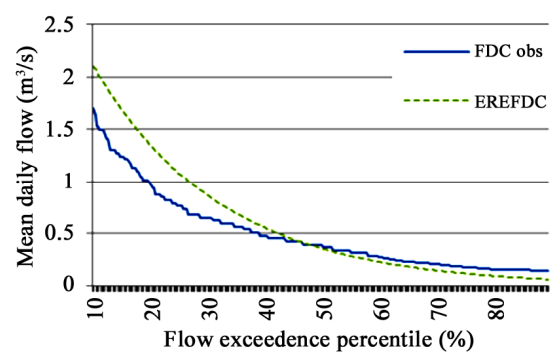

(d)

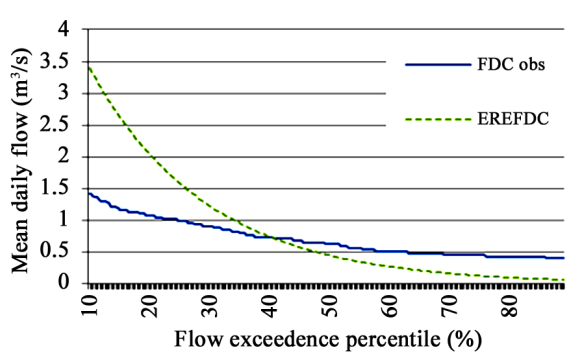

(g)

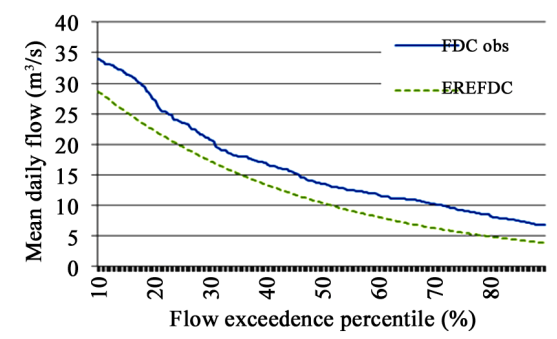

(b)

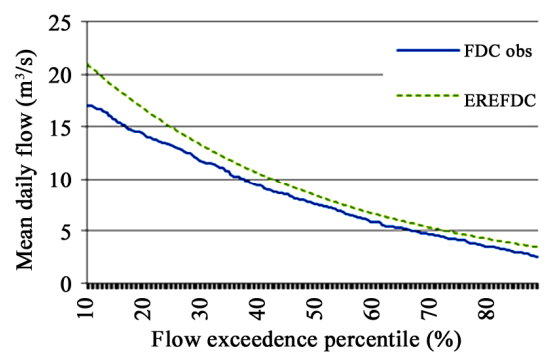

(e)

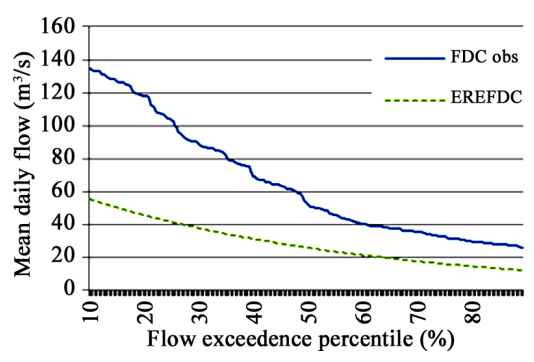

(h)
Table 3. (a) Randomly selected test stations from Table 2(a); (b) Randomly selected test stations from Table 2(b).

(a)

\begin{tabular}{ccc}
\hline Station Number & Station Name & Carstic Non-carstic \\
\hline 84400 & Little Blue R. & Non-Carstic \\
6913000 & M. des Cygnes R. & Non-Carstic \\
7140850 & Pawnee R. & Non-Carstic \\
7141780 & Walnut C. & Non-Carstic \\
7144200 & Little Arkansas R. & Non-Carstic \\
7152000 & Chikaskia R. & Non-Carstic \\
7157500 & Crooked C. & Non-Carstic \\
7183500 & Neosho R. & Non-Carstic \\
7186000 & Spring R. & Non-Carstic \\
\hline
\end{tabular}

(b)

\begin{tabular}{ccc}
\hline Station Number & Station Name & Carstic Non-carstic \\
\hline 6863500 & Big C. & Carstic \\
6888500 & Mill C. & Carstic \\
6911000 & M.des Cygnes R. & Carstic \\
7157950 & Cimarron R. & Carstic \\
7180500 & Cedar C. & Carstic \\
\hline
\end{tabular}

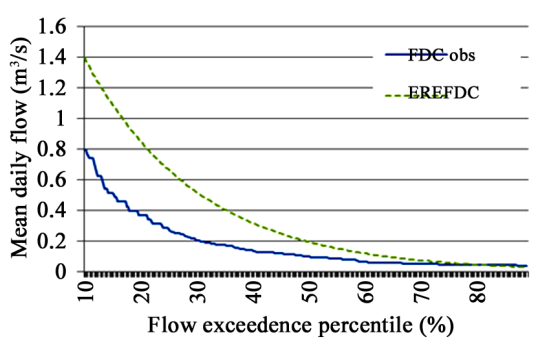

(c)

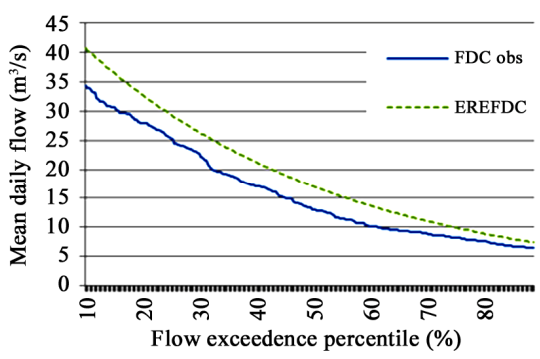

(f)

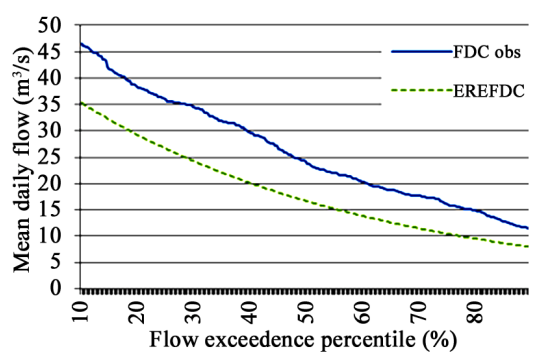

(i)

Figure 4. (a) Test station number 06884400; (b) Test station number 06913000; (c) Test station number 07140850; (d) Test station number 07141780; (e) Test station number 07144200; (f) Test station number 07152000; (g) Test station number 07157500; (h) Test station number 07183500 ; (i) Test station number 07186000. 


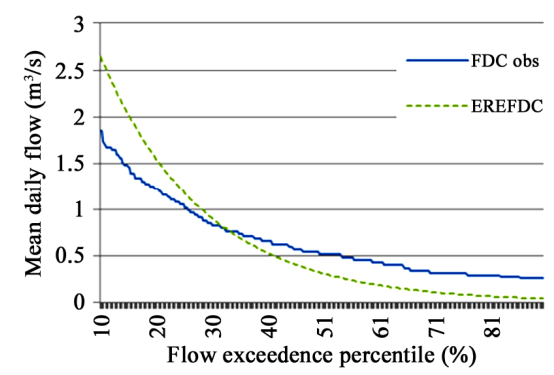

(a)

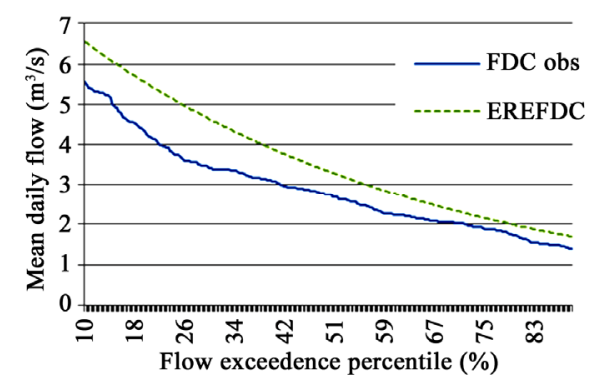

(d)

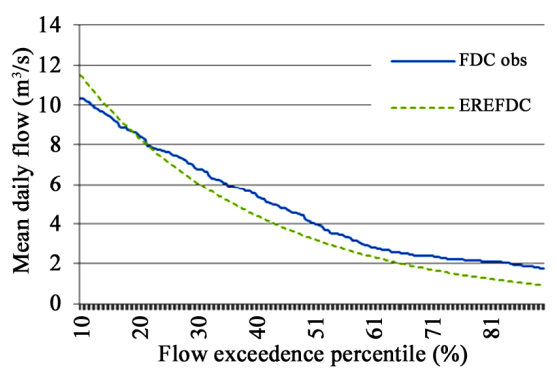

(b)

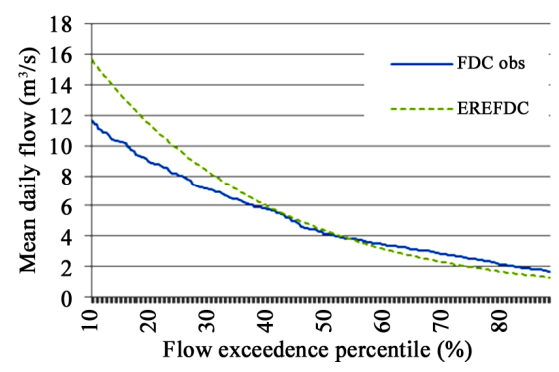

(c)

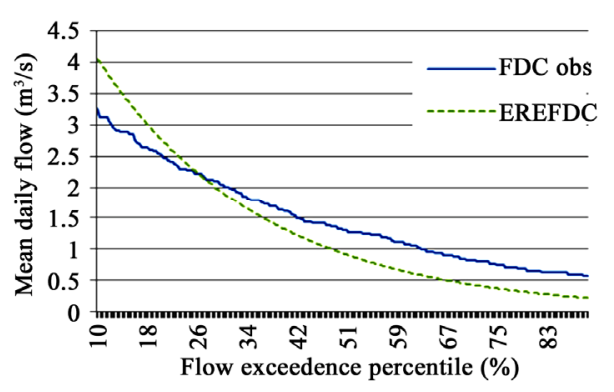

(e)

Figure 5. (a) Test station number 06863500; (b) Test station number 06888500; (c) Test station number 06911000; (d) Test station number 07157950 ; (e) Test station number 0718050.

Table 4. Average relative errors between observed stream flow and EREFDC model $10 \%$ and $90 \%$ flow exceedence.

\begin{tabular}{cccc}
\hline \multirow{4}{*}{ Station Number } & Station Name & Relative Error (\%) \\
\cline { 2 - 4 } & 6884400 & Little Blue R. & 11 \\
& 6913000 & M. des Cygnes R. & 28 \\
Non-carstic & 7140850 & Pawnee R. & 88 \\
Region & 7141780 & Walnut C. & 28 \\
& 7152000 & L. Arkansas R. & 15 \\
& 7157500 & Chikaskia R. & 23 \\
& 7183500 & Crooked C. & 58 \\
& 7186000 & Neosho R. & 54 \\
& Average Relative Errors & 31 \\
\hline \multirow{3}{*}{ Carstic } & 6888500 & Mill C. & 37 \\
\cline { 2 - 4 } Region & 6911000 & M.des Cygnes R. & 16 \\
& 7157950 & Cimarron R. & 23 \\
& 7180500 & Cedar C. & 31 \\
& Average Relative Errors & 27 \\
\hline
\end{tabular}

\section{Conclusions}

This study deals with the prediction of flow-durationcurves for ungauged hydrological basins. For this pur- pose two-step procedure is proposed. At Step I, the FDC parameters are obtained for each gauged station by grouping the stations as carstic and non-carstic. The FDC parameters are obtained with Excel solver toolbox. Step 1 by using the data at this, regionalization is made with geographical, physical and hydrological data given in Table 1. For this aim, the EREFDC regional model is proposed that is quadratic type that is solved with BFGS algorithm. The following results may be drawn from this study:

1) Prediction of FDC at ungauged hydrological basins may be estimated with the proposed EREFDC model by errors of $27 \%$ to $37 \%$ for carstic and non-carstic hydrological basins using the mathematical optimization technique called BGFC algorithm.

2) Two-step approach may be useful to obtain the FDC parameters in order to regionalize the FDC model in a carstic and non-carstic basins.

3) The EREFDC model is applied to 72 unimpaired catchments in USGS in USA for 60 years average daily measured stream-flow. Results showed that parameters of FDC for tributaries at the upper basins with insufficient flow data or without flow data may be determined by using basin characteristics for studied area.

4) Results showed that the EREFDC model provided about $37 \%$ average relative error for non-carstic and $27 \%$ for carstic basins. Thus, it could be possible to say that the EREFDC provides quite better performance in carstic regions than non-carstic regions.

5) This study focuses on the development of regional mathematical model for estimating parameters of FDC 
curves for carstic and non-carstic regions. The average relative errors may be considered as a quite high for noncarstic regions. Future studies should be improvement on the prediction performance of the ERFDC model for uncontrolled steam flows for various data in the world.

\section{REFERENCES}

[1] R. M. Vogel and N. M. Fennessey, "Flow Duration Curves II: A Review of Applications in Water Resources Planning," Journal of the American Water Resources Association, Vol. 31, No. 6, 1995, pp. 1029-1039. doi:10.1111/j.1752-1688.1995.tb03419.x

[2] C. C. Warnick, "Hydropower Engineering," Englewood Cliffs, New Jersey, 1984.

[3] D. R. Maidment, "Handbook of Hydrology," McGrawHill, Colombus, 1992.

[4] N. Fennessey and R. M. Vogel, "Regional Flow Duration Curves for Ungauged Sites in Massachusetts," Journal of Water Resources Planning and Management, Vol. 116, No. 4, 1990, pp. 530-549. doi:10.1061/(ASCE)0733-9496(1990)116:4(530)

[5] M. Mimikou and S. Kaemaki, "Regionalization of Flow Duration Characteristics," Journal of Hydrology, Vol. 82, No. 1-2, 1985, pp. 77-91. doi:10.1016/0022-1694(85)90048-4

[6] A. Alkan, "Karst Pinar Katkili Akarsularda, Serbest Yüzeyli Akişli Çevirme Santralları için Akım Sürek Eğrilerinin Modellenmesi," III. Ulusal Hidroloji Kongresi, İzmir, 2001, pp. 247-255.

[7] R. D. Singh, S. K. Mishra and H. Chowdhary, "Regional Flow-Duration Models for Large Number of Ungauged Himalayan Catchments for Planning Microhydro Projects, Journal of Hydrologic Engineering, Vol. 6, No. 4, 2001, pp. 310-316.

doi:10.1061/(ASCE)1084-0699(2001)6:4(310)

[8] P. S. Yu and T. C. Yang, "Uncertainty Analysis of Regional Flow Duration Curves," Journal of Water Resources Planning and Management, Vol. 128, No. 6, 2002, pp. 424-430. doi:10.1061/(ASCE)0733-9496(2002)128:6(424)

[9] M. Franchini and M. Suppo, "Regional Analysis of Flow Duration Curves for a Limestone Region," Water Resources Management, Vol. 10, No. 3, 1996, pp. 199-218. doi:10.1007/BF00424203

[10] P. S. Yu and T. C. Yang, "Synthetic Regional Flow Duration Curve for Southern Taiwan," Hydrological Processes, Vol. 10, No. 3, 1996, pp. 373-391.

doi:10.1002/(SICI)1099-1085(199603)10:3<373::AID-H YP306>3.0.CO;2-4

[11] K. M. Crocker, M. D. Z. Young and H. G. Rees, "Flow Duration Curve Estimation in Ephemeral Catchments in Portugal," Hydrological Sciences, Vol. 48, No. 3, 2003, pp. 427-439. doi:10.1623/hysj.48.3.427.45287

[12] R. A. J. Cole, H. T. Johnston and D. J. Robinson, "The Use of Flow Duration Curves as a Data Quality," Hydrological Sciences, Vol. 48, No. 6, 2003, pp. 939-951.
[13] I. Krasovskaia, I. Gottschalk, E. Leblois and A. Pacheco, "Regionalization of Flow Duration Curves," In: S. Demuth, Ed., Climate Variability and Change-Hydrological Impacts, IAHS Press, Wallingford, 2006.

[14] M. F. Bari and Kh. M. D. S. Islam, "Stochastic Model of Flow Duration Curves for Selected Rivers in Bangladesh," Proceedings of the 5th FRIEND World Conference on Climate Variability and Change-Hydrological Impacts, Havana, 27 November-1 December 2006, pp. 99-104.

[15] I. A. Niadas, "Regional Flow Duration Curve Estimation in Small Ungauged Catchments Using Instantaneous Flow Measurements and a Censored Data Approach," Journal of Hydrology, Vol. 314, No. 1-4, 2005, pp. 48-66. doi:10.1016/j.jhydrol.2005.03.009

[16] A. Castellarin, G. Galeati, L. Brandimatre, A. Montanari and A. Brath, "Regional Flow-Duration Curves: Reliability for Ungauged Basins," Advances in Water Resources, Vol. 27, No. 10, 2004, pp. 953-965. doi:10.1016/j.advwatres.2004.08.005

[17] L. Ming, S. Quanxi, Z. Lu and H. S. C. Francis, “A New Regionalization Approach and Its Application to Predict Flow Duration Curve in Ungauged Basins," Journal of Hydrology, Vol. 389, No. 1-2, 2010, pp. 137-145. doi:10.1016/j.jhydrol.2010.05.039

[18] D. Ganora, P. Claps, F. Laio and A. Viglione, "An Approach to Estimate Nonparametric Flow Duration Curves in Ungauged Basins," Water Resources Research, Vol. 45, 2009, W10418. doi:10.1029/2008WR007472

[19] Y. Yokoo and M. Sivapalan, "Towards Reconstruction of the Flow Duration Curve: Development of a Conceptual Framework with a Physical Basis," Hydrology and Earth System Sciences, Vol. 15, No. 9, 2011, pp. 2805-2819.

[20] F. Viola, L. V. Noto, M. Cannarozzo and G. La Loggia, "Regional Flow Duration Curves for Ungauged Sites in Sicily," Hydrology and Earth System Sciences, Vol. 15, No. 1, 2011, pp. 323-331.

[21] Microsoft, "Microsoft Excel-Visual Basic for Applications," Microsoft Press, Washington DC, 1995.

[22] H. C. Riggs, "Low-Flow Investigations," US Geological Survey Techniques of Water-Resources Investigations, Washington DC, 1972.

[23] L. C. Kjelstrom, "Methods for Estimating Selected FlowDuration and Flood-Frequency Characteristics at Ungauged Sites in Central Idaho," USGS Water Resources Investigations Report 94-4120, Boise, 1998, p. 10.

[24] S. E. Studley, "Estimated Flow Duration Curves for Selected Ungauged Sites in Kansas," US Geological Survey, 01:4142, Virginia, 2001.

[25] J. Nocedal and S. J. Wright, "Numerical Optimization," Springer-Verlag, Berlin, 2006.

[26] J. S. Arora, "Introduction to Optimum Design," McGrawHill, New York, 1989.

[27] H. Karahan, G. Gurarslan and Z. W. Geem, "Parameter Estimation of the Nonlinear Muskingum Flood Routing Model Using a Hybrid Harmony Search Algorithm," Journal of Hydrologic Engineering, 2012, in Press. doi:10.1061/(ASCE)HE.1943-5584.0000608 
[28] C. A. Perry, D. M. Volock and J. C. Artman, "Estimates of Flow Duration, Mean Flow and Peak-Discharge Frequency Values for Kansas Stream Location," Scientific
Investigation Report 2004-5033, US Geological Survey, Virginia, 2004. 
Appendix: Example average daily flow for Turkey C. station.

\begin{tabular}{|c|c|c|c|c|c|c|c|c|c|c|c|c|}
\hline \multicolumn{13}{|c|}{06814000 - TURKEY C NR SENECA, KS Daily Mean Flows for 62 years } \\
\hline & Jan & Feb & Mar & Apr & May & Jun & Jul & Aug & Sep & Oct & Nov & Dec \\
\hline 1 & 0.79 & 2.89 & 4.96 & 8.27 & 6.26 & 4.53 & 9.26 & 1.81 & 1.42 & 3.34 & 1.30 & 1.27 \\
\hline 2 & 0.79 & 2.32 & 4.33 & 5.10 & 5.15 & 9.01 & 5.30 & 1.81 & 3.82 & 4.56 & 3.17 & 0.88 \\
\hline 3 & 0.76 & 1.90 & 7.02 & 8.67 & 3.26 & 5.49 & 3.12 & 2.38 & 3.09 & 4.30 & 2.10 & 0.79 \\
\hline 4 & 0.74 & 2.24 & 4.45 & 6.23 & 3.09 & 5.15 & 5.07 & 2.10 & 8.04 & 1.56 & 1.84 & 0.82 \\
\hline 5 & 0.74 & 1.78 & 5.41 & 4.96 & 4.25 & 3.51 & 9.23 & 1.08 & 5.04 & 1.19 & 1.10 & 0.85 \\
\hline 6 & 0.76 & 1.67 & 4.13 & 4.11 & 6.83 & 6.03 & 5.89 & 2.83 & 3.74 & 1.56 & 0.88 & 0.74 \\
\hline 7 & 0.85 & 1.67 & 3.14 & 3.00 & 14.30 & 6.17 & 9.40 & 4.16 & 5.30 & 2.12 & 0.96 & 0.74 \\
\hline 8 & 1.05 & 1.50 & 2.49 & 2.80 & 14.02 & 4.87 & 4.05 & 4.16 & 2.66 & 1.87 & 1.22 & 1.02 \\
\hline 9 & 0.88 & 1.47 & 3.09 & 3.09 & 10.56 & 5.64 & 5.86 & 1.73 & 4.59 & 2.32 & 1.98 & 0.85 \\
\hline 10 & 0.93 & 1.42 & 3.94 & 3.12 & 6.97 & 8.18 & 4.90 & 1.53 & 2.72 & 3.91 & 1.44 & 0.82 \\
\hline 11 & 0.79 & 1.81 & 5.58 & 4.13 & 5.66 & 5.04 & 10.54 & 1.81 & 1.42 & 10.85 & 0.91 & 1.02 \\
\hline 12 & 1.19 & 2.10 & 5.95 & 4.02 & 4.59 & 7.39 & 7.90 & 1.70 & 6.71 & 7.08 & 1.25 & 1.19 \\
\hline 13 & 1.81 & 2.24 & 4.81 & 3.00 & 7.90 & 6.66 & 5.75 & 2.21 & 6.57 & 2.44 & 1.39 & 1.02 \\
\hline 14 & 1.13 & 2.21 & 5.66 & 5.78 & 3.17 & 5.52 & 3.85 & 1.98 & 2.86 & 2.07 & 1.08 & 1.30 \\
\hline 15 & 1.56 & 2.18 & 3.77 & 8.30 & 5.69 & 9.88 & 3.43 & 3.03 & 2.24 & 5.30 & 0.82 & 1.05 \\
\hline 16 & 1.08 & 2.55 & 3.34 & 4.13 & 5.75 & 9.23 & 2.24 & 1.78 & 2.52 & 1.76 & 1.84 & 0.85 \\
\hline 17 & 1.36 & 3.09 & 3.68 & 5.35 & 8.67 & 5.81 & 2.78 & 1.44 & 4.08 & 1.44 & 2.24 & 0.85 \\
\hline 18 & 1.27 & 4.76 & 8.95 & 5.55 & 4.64 & 10.54 & 8.04 & 1.33 & 1.61 & 1.67 & 1.36 & 0.91 \\
\hline 19 & 1.05 & 5.24 & 8.47 & 2.95 & 4.79 & 6.60 & 3.60 & 1.84 & 2.04 & 1.13 & 1.84 & 1.08 \\
\hline 20 & 0.96 & 3.94 & 3.77 & 3.57 & 4.05 & 3.74 & 6.74 & 2.04 & 2.61 & 1.33 & 1.73 & 0.85 \\
\hline 21 & 1.05 & 2.80 & 3.34 & 5.61 & 8.44 & 6.06 & 3.14 & 1.47 & 3.46 & 1.25 & 1.53 & 0.79 \\
\hline 22 & 1.02 & 2.18 & 3.34 & 4.98 & 9.01 & 5.38 & 6.37 & 1.93 & 2.49 & 1.13 & 1.10 & 0.76 \\
\hline 23 & 1.13 & 2.49 & 5.07 & 3.57 & 7.05 & 5.55 & 6.46 & 1.42 & 2.15 & 1.05 & 0.85 & 0.85 \\
\hline 24 & 1.70 & 4.47 & 5.38 & 3.94 & 6.32 & 5.75 & 4.16 & 2.35 & 1.67 & 1.02 & 1.47 & 0.88 \\
\hline 25 & 1.16 & 4.08 & 6.66 & 4.73 & 5.10 & 7.11 & 9.86 & 2.27 & 2.21 & 0.71 & 0.99 & 1.19 \\
\hline 26 & 1.44 & 3.96 & 5.89 & 4.39 & 7.31 & 4.70 & 4.87 & 1.67 & 2.78 & 0.76 & 0.99 & 0.88 \\
\hline 27 & 2.01 & 3.88 & 8.10 & 8.86 & 7.59 & 4.96 & 2.86 & 1.39 & 4.02 & 0.74 & 0.88 & 1.08 \\
\hline 28 & 1.93 & 4.08 & 9.32 & 3.60 & 5.30 & 6.83 & 3.40 & 2.41 & 3.06 & 0.68 & 0.79 & 0.93 \\
\hline 29 & 1.95 & 1.05 & 6.40 & 3.68 & 5.04 & 14.67 & 1.42 & 2.55 & 4.53 & 0.85 & 0.79 & 0.93 \\
\hline 30 & 1.87 & & 10.22 & 5.30 & 6.94 & 6.00 & 2.44 & 2.52 & 2.83 & 1.56 & 1.16 & 1.42 \\
\hline 31 & 1.53 & & 10.68 & & 7.59 & & 2.04 & 0.93 & & 1.44 & & 1.02 \\
\hline
\end{tabular}

